\title{
Analytic Hierarchy Process-based University Students Sports Elective Course Development and Influence Factors Research
}

\author{
Chao Huang ${ }^{*}$ \\ Institute of Physical Education, Gannan Normal University, Ganzhou 341000, Jiangxi, China
}

\begin{abstract}
Contemporary university students are motherland beams and main forces of social construction. Therefore, just relying on passing the cultural knowledge is not enough. Rather, university students need to be cultivated as qualified and talented all-rounders. Only then can the contemporary university students progress with socialism construction tide. In this regard, the sports elective course has become an indispensible part of the university education. This paper utilizes analytic hierarchy process method, establishes a university elective course influential AHP model, and by comparing weights, calculates the highest option rate of the university students for the sports course. Starting from the students themselves, moving on to the teachers, the teaching process, management, field availability, apparatus and through other aspects, conclusions are drawn based on the analysis of the numerous factors that affect the university students electing the sports courses. Secondly, on the basis of the factors, analytic hierarchy process is utilized to establish target layer, scheme layer and criterion layer by conducting calculation and analysis. The results suggest that the students, teachers, teaching process, management, field availability, apparatus and other various factors, all have certain impacts on the university students' opting for the sports elective courses. In the current stage in the universities of China, the highest option rate among the students for sports elective course is of badminton, while table tennis and basketball come next.
\end{abstract}

Keywords: Analytic hierarchy process, hierarchical structure, influence factor, sports elective course, university sports.

\section{INTRODUCTION}

With constant reformation in the education of the universities in China, physical education has transformed from previous single sports general course into multiple sports elective course. The education reformation has not only enhanced students' positivity for participating in sports, but also has been helpful for school teachers' teaching management [1-3].

By consulting lots of relative literatures and discoveries, in 2008, Zheng Gui-Feng, Zhou Li-Bao in the article "Regular universities sports elective course setting status investigation", selected five universities of China as investigation and research objects, and analyzed present physical elective course status of the university students [4-6].

In 2006, Yao Yong-Wei in the article "Xingtai city higher vocational college sports elective course organization status research", collected a great deal of relevant literatures, and adopted investigation, statistics and other methods, by analyzing universities' sports elective course status, obtaining corresponding conclusions $[7,8]$.

In 2001, Huang Song-Feng, Lin Yang-Suo in the article "University students sports elective courses selection influential factors research", focused on Yunnan Normal University public sports elective course, selected grade 09 university students as research objects, adopted questionnaire survey, data analysis and other methods to analyze the influential numerous factors for sports elective course of China university.

*Address correspondence to this author at the Institute of Physical Education, Gannan Normal University, Ganzhou 341000, Jiangxi, China; Tel: +86-15524646838; E-mail: 15524646838@163.com
This paper on the basis of research on China university students for sports elective course, and references from summarized experiences and literatures, studies the influential factors affecting the choice for sports elective course, starting from the perspective of the university students, to comprehensive analysis of the activities of the students and the teachers, the teaching process, the management factor, and also the venues and equipment factors. By using mathematical methods, the paper further establishes the analytic hierarchy process model, obtaining the present maximum selection odds in the physical education courses of the China university students.

\section{RECENT YEARS' CHINESE UNIVERSITY STU- DENTS' SPORTS ELECTIVE COURSES STATUS}

Sports elective course is one compulsory course in higher vocational colleges; its setting not only promotes students' lifelong sports consciousness, but can also promote students' physical quality. Table 1 below shows the statistical analysis table of the setting purposes of sports elective course in Chinese universities. Further, statistical analysis is conducted as follows, giving conclusions:

In order to more conveniently observe and analyze, the above table is transformed into pie Fig. (1) as follows:

From Table $\mathbf{1}$ and Fig. (1), it can be clearly seen that cultivation of students' consciousness for lifelong sports and motivating students to take an active part in sports are main purposes of Chinese vocational colleges sports elective course setting purposes; second purpose involves improving the students' sports ability and technology; the third is to improethe comprehensive ability of students and their ability of social adaptation; finally, to cultivate the students' 

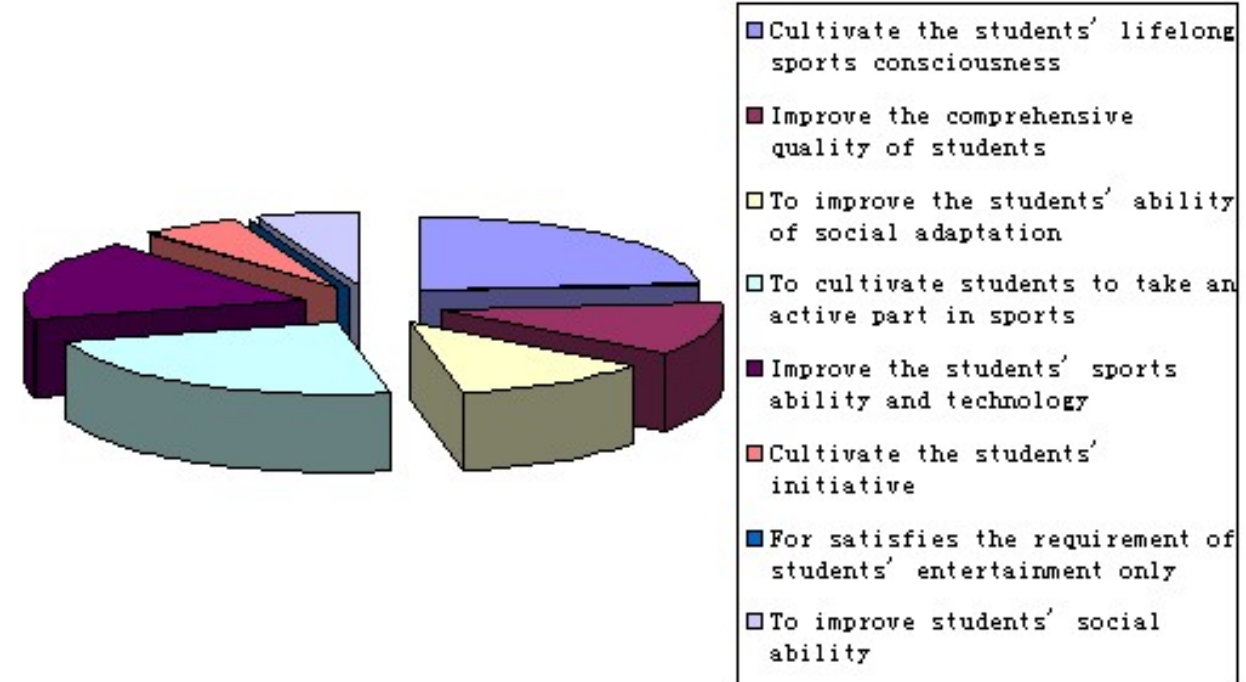

Fig. (1). Open the purpose of sports elective course in higher vocational colleges.

Table 1. Chinese vocational colleges' sports elective course setting purpose.

\begin{tabular}{|c|c|c|}
\hline Content & School & Number of Frequency \\
\hline Cultivate the students' lifelong sports consciousness & 5 & 100 \\
\hline Improve the comprehensive ability of students & 2 & 50.00 \\
\hline To improve the students' ability of social adaptation & 2 & 50.00 \\
\hline To cultivate the students to take an active part in sports & 4 & 100 \\
\hline Improve the students' sports ability and technology & 3 & 75.00 \\
\hline Cultivate the students' initiative & 1 & 25.00 \\
\hline For satisfying the requirement of students' entertainment only & 0 & 0 \\
\hline To improve students' social ability & 1 & 25.00 \\
\hline
\end{tabular}

initiatives and improve students' social ability. In order to make it easier to observe, Table $\mathbf{2}$ is transformed into bar Fig. (2), as follows:

By Table 2 and Fig. (2), it can be seen that among vocational colleges, sports elective courses which have syllabus and teaching materials are fewer, though most the colleges have evaluation standards for sports elective courses. Still it can be seen that there is no existence of perfect management for Chinese vocational colleges' sports elective course.

\section{UNIVERSITY STUDENTS ELECTIVE COURSE INFLUENTIAL ANALYTIC HIERARCHY PROCESS MODEL}

At present, contemporary influential factors for university students' sports elective course involve students' own factors, teachers' factors, teaching, management factors, venues and equipment factors etc. This paper therefore establishes the analytic hierarchy process model, and conducts quantization on university students' sports elective course orientations, by establishing target layer, criterion layer, and scheme layer relations. Finally present highest selection odds in sports courses of Chinese university students are presented.

AHP is based on posed problems' requirements and properties, which divide contained factors into target layer, criterion layer and scheme layer, so that a hierarchical shape structure is constituted. It further makes paired mutual comparison of each factor in the same layer, and defines next layer weight with respect to previous layer target. By analyzing every layer, finally, it ranks each factor of the target layer, criterion layer and scheme layer having factor importance degree as the total target. Its main features are reasonably combined qualitative and quantitative decisions so that decision process is layered and quantified.

Target layer: College students' sports elective course

Criterion layer: Scheme influence factors, $C_{1}$ : students' own factors, $C_{2}$ : teachers' factors, $C_{3}$ : teaching and management factors, $C_{4}$ : venues and equipment factors.

Scheme layer: $A_{1}$ is badminton, $A_{2}$ is table tennis, $A_{3}$ is basketball. 


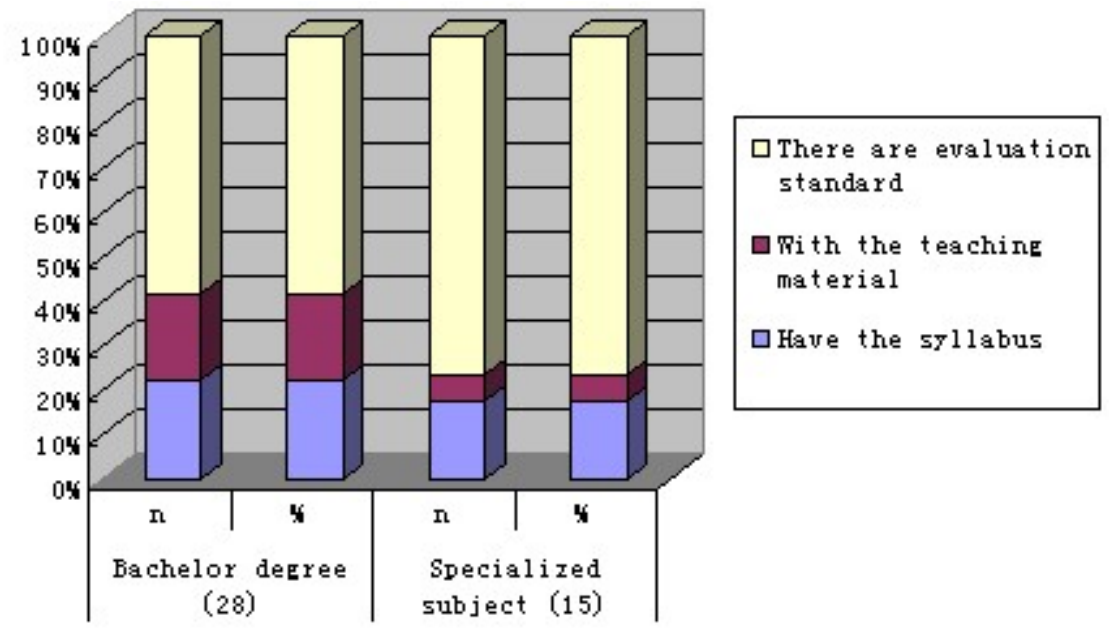

Fig. (2). Elective course syllabus of statistical list.

Table 2. Elective course syllabus status statistics table.

\begin{tabular}{|c|c|c|c|c|}
\hline & Bachelor Degree (28) & Specialized Subject (15) & n & \% \\
\cline { 2 - 5 } & $\mathbf{n}$ & 28.6 & 3 & 20.0 \\
\hline \hline Have the syllabus & 8 & 25.0 & 1 & 13 \\
\hline With the teaching material & 7 & 75.0 & 8.7 \\
\hline There are evaluation standard & 21 & 86.7 & \\
\hline
\end{tabular}

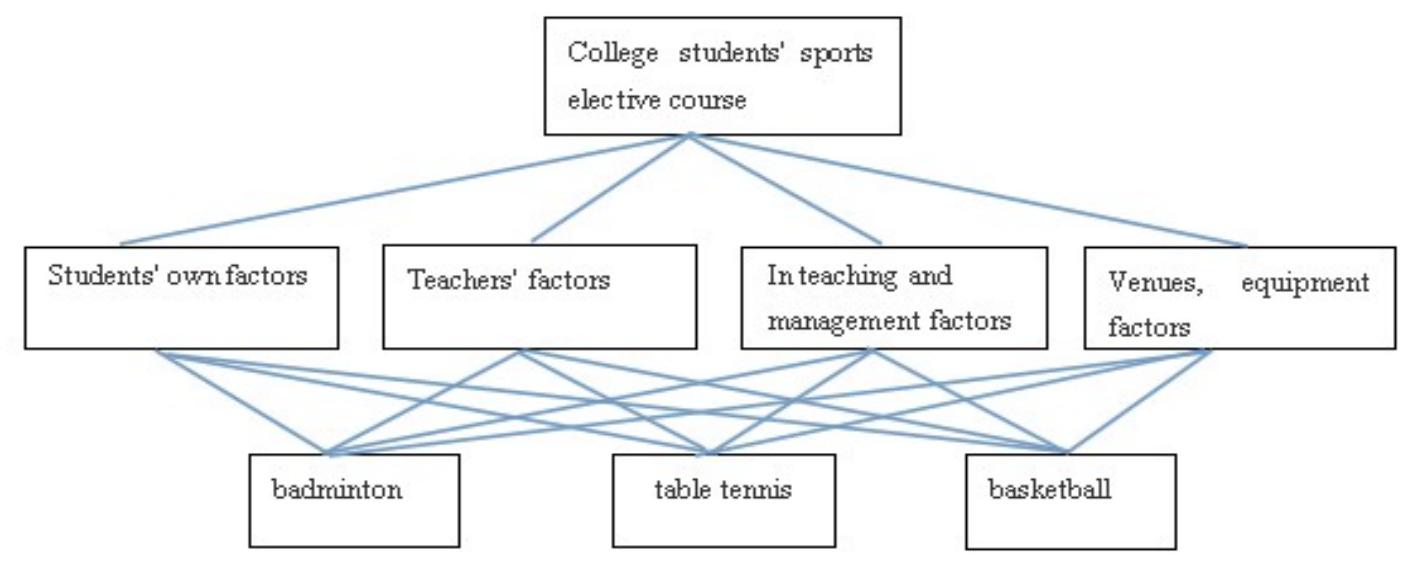

Fig. (3). The hierarchical structure of the university sports elective course.

By analyzing influence factors for college students' sports elective course, layer relative influence factors from top to down show that preceding layer is influenced by the next layer, with each layer factors being relatively independent. Therefore, following hierarchical structure is obtained as shown in Fig. (3).

Primary factors that affect university students inclination for sports elective course are the students' own factors, including mainly their interests and hobbies, selection purposes and motivations, gender differences, physiological and psychological endurances, physical statuses, requirements of credit and future working practices and other elements.

When students select different sports courses, most of them except for considering personal factors, also take into consideration teacher professional ethics, their professional proficiency, teachers' individual charm, their language orientation and other related factors.

Elective course setting, faculty equipping, teaching hours and credits distribution comprise teaching and management factors in university students' sports elective course. Whether elective course setting can meet students' aspiration or not, this factor is very important for students selection; faculty equipping is important for ensuring the quality of the elective course, and meanwhile, it also reflects a school's strength for maintaining the setting of an elective course to certain extent; students in elective course, except for learning one favorite sports course, consider whether there are more class hours and easy credits to acquire,; therefore, the ten- 
Table 3. 1 9 scale definition.

\begin{tabular}{|c|c|}
\hline Scale $a_{i j}$ & Definition \\
\hline \hline 1 & factor i and factor $\mathrm{j}$ have equal importance \\
\hline 3 & factor $\mathrm{i}$ is slightly more important than factor $\mathrm{j}$ \\
\hline 5 & factor $\mathrm{i}$ is relative more important than factor $\mathrm{j}$ \\
\hline 7 & factor $\mathrm{i}$ is extremely more important than factor $\mathrm{j}$ \\
\hline 9 & factor $\mathrm{i}$ is absolute more important than factor $\mathrm{j}$ \\
\hline $2,4,6,8$ & Indicates middle state corresponding scale value of above judgments \\
\hline Reciprocal of above each value & $\begin{array}{r}\text { If compare indicator } i \text { with indictor } j \text {, the relative importance use above one numeric value scale, then } \\
\text { indicator } j \text { and indicator } i \text { relative importance use above numeric value reciprocal scale }\end{array}$ \\
\hline
\end{tabular}

dency of teaching hours and credits distribution being reasonable is one of the multiple important factors that affect opting for sports elective course.

Venues and equipment involve sports hardware that mainly include venues, equipment quantity, sports venue environment, equipment quality, and facilities functions. Venues and equipment quantity have certain limitations on the number of people electing the course, that often refrain some students from selecting their favorite sports course; sports venue environment however, further divides into indoor venues and outdoor venues, as some students like exercising in outdoors, while some like indoors, therefore students can select different sports courses according to their requirements and equipment. And as facility functions get more complete, students exercise more contents, and therefore more students are attracted to participate.

For carrying out paired comparison among elements, the matrix is used to express element importance of each layer to all the elements of the previous layer. Here $1 \sim 9$ ratio scale proposed by operational research expert is applied, as shown in Table 3.

According to the above scale in Table 3, judgment matrix $A$ is set as:

$$
A=\left(\begin{array}{cccc}
1 & 2 & 4 & 3 \\
\frac{1}{2} & 1 & 5 & 5 \\
\frac{1}{4} & \frac{1}{5} & 1 & 1 \\
\frac{1}{3} & \frac{1}{5} & 1 & 1
\end{array}\right)
$$

Obviously, $A$ is positive reciprocal matrix.

Consistency matrix definitions and property:

a. Consistency matrix's definition: Positive reciprocal matrix that meets $a_{i j} * a_{j k}=a_{i k}, i, j=1,2, \cdots, n$ is consistency matrix. For example:

$$
A=\left(\begin{array}{cccc}
\frac{w_{1}}{w_{1}} & \frac{w_{1}}{w_{2}} & \cdots & \frac{w_{1}}{w_{n}} \\
\frac{w_{2}}{w_{1}} & \frac{w_{2}}{w_{2}} & \cdots & \frac{w_{2}}{w_{n}} \\
\vdots & \vdots & \ddots & \vdots \\
\frac{w_{n}}{w_{1}} & \frac{w_{n}}{w_{2}} & \cdots & \frac{w_{n}}{w_{n}}
\end{array}\right)
$$

b. Consistency matrix property: matrix $A$ order is $1, A$ unique non-zero feature root is $n$. Matrix $A$ any one column vector is a feature vector that corresponds to $n$. Matrix $A$ normalized feature vector can be used as weight vector.

However, in above constructed comparison matrix $\begin{aligned} A= & \left(\begin{array}{cccc}1 & 2 & 4 & 3 \\ \frac{1}{2} & 1 & 5 & 5 \\ \frac{1}{4} & \frac{1}{5} & 1 & 1 \\ \frac{1}{3} & \frac{1}{5} & 1 & 1\end{array}\right) \\ & \text { Because } a_{12}=\frac{C_{1}}{C_{2}}=2, a_{13}=\frac{C_{1}}{C_{3}}=4, \text { so } a_{23}=\frac{C_{2}}{C_{3}}=2,\end{aligned}$ while actually $a_{23}=5$. So $A$ is not consistency matrix. In general, for inconsistent (but in permissible range) paired comparison matrix $A$, feature vector is suggested to use that corresponds to maximum feature root $\lambda$ as weight vector.

Consistency indicator: $C I=\frac{\lambda_{\max }-n}{n-1}$. Among them, $\lambda_{\max }$ is a maximum feature value of comparison matrix and $\mathrm{n}$ is the order of comparison matrix. When $n$ order positive reciprocal matrix maximum feature root $\lambda \geq n$, and $\lambda=n$, it is consistency matrix. When $C I$ value gets 
smaller, judgment gets closer to being fully consistent. On the contrary, judgment matrix consistency deflection degree will be bigger.

Random consistency indicator Table 4: By randomly generating multiple matrixes, and adding every matrix's consistency indicator and then taking average value, $R I$ is obtained.

Consistency ratio: If $C R=\frac{C I}{R I}<0.1$, constructed paired comparison matrix $A$ passes consistency test.

By calculation, paired comparison matrix $A$ maximum feature value can be obtained $\lambda_{\max }=4.239, R I=0.89$

By consistency indicator $C I=\frac{\lambda_{\max }-n}{n-1}$, input data, by calculating, $C I=\frac{4.239-4}{4-1}=0.08$. And by consistency ratio $C R=\frac{C I}{R I}=\frac{0.08}{0.89}=0.089<0.1$, it is obvious that constructed paired comparison matrix $A$ passes consistency test.

Constructed scheme layer judgment matrixes correspond to different criterion layers as shown in Tables 5-8.

Calculate weight vector, to $A=\left(\begin{array}{cccc}1 & 2 & 4 & 3 \\ \frac{1}{2} & 1 & 5 & 5 \\ \frac{1}{4} & \frac{1}{5} & 1 & 1 \\ \frac{1}{3} & \frac{1}{5} & 1 & 1\end{array}\right)$, firstly handling is as following:

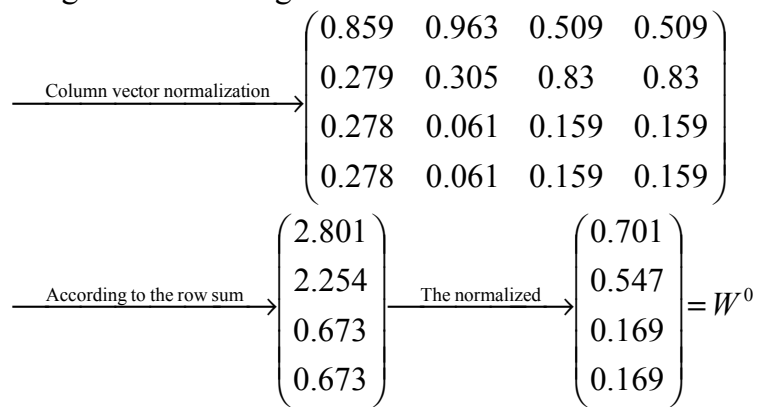

And then, by $A \times W^{0}$ further solved $\lambda^{0}{ }_{\text {max }}=4.239$.

Similarly, criterion layer judgment matrix maximum feature value and weight solved are as following: $\lambda_{\text {max }}^{1}=3.62, W_{1}=\left(\begin{array}{l}0.213 \\ 0.223 \\ 0.492\end{array}\right) ; \lambda^{2}{ }_{\max }=3.31, W_{2}=\left(\begin{array}{l}0.647 \\ 0.249 \\ 0.061\end{array}\right)$; $\lambda_{\text {max }}^{3}=3.29, W_{1}=\left(\begin{array}{l}0.607 \\ 0.195 \\ 0.137\end{array}\right) ; \lambda_{\text {max }}^{4}=3.29, W_{4}=\left(\begin{array}{l}0.597 \\ 0.199 \\ 0.146\end{array}\right)$

And by utilizing above principle to judge, it is clear that all matrixes pass the consistency test.

By $W^{1}=\left(W_{1}, W_{2}, W_{3}, W_{4}\right)$, and $W=W^{1} \times W^{0}$ it can calculate and get $W=\left(\begin{array}{l}0.479 \\ 0.220 \\ 0.301\end{array}\right)$.

Table 4. Random consistency indicator.

\begin{tabular}{|c|c|c|c|c|c|c|c|c|c|c|c|}
\hline$n$ & 1 & 2 & 3 & 4 & 5 & 6 & 7 & 8 & 9 & 10 & 11 \\
\hline$R I$ & 0 & 0 & 0.58 & 0.90 & 1.12 & 1.24 & 1.32 & 1.41 & 1.45 & 1.49 & 1.51 \\
\hline
\end{tabular}

Table 5. Criterion layer judgment matrix B1.

\begin{tabular}{|c|c|c|c|}
\hline$C_{1}$ & $A_{1}$ & $A_{2}$ & $A_{3}$ \\
\hline \hline$A_{1}$ & 1 & 1 & $1 / 3$ \\
\hline$A_{2}$ & 1 & 1 & $1 / 3$ \\
\hline$A_{3}$ & 3 & 3 & 1 \\
\hline
\end{tabular}

Table 6. Criterion layer judgment matrix B2.

\begin{tabular}{|c|c|c|c|}
\hline$c_{2}$ & $A_{1}$ & $A_{2}$ & $A_{3}$ \\
\hline \hline$A_{1}$ & 1 & 5 & 5 \\
\hline$A_{2}$ & $1 / 5$ & 1 & 5 \\
\hline$A_{3}$ & $1 / 5$ & $1 / 5$ & 1 \\
\hline
\end{tabular}


Table 7. Criterion layer judgment matrix B3.

\begin{tabular}{|c|c|c|c|}
\hline$c_{3}$ & $A_{1}$ & $A_{2}$ & $A_{3}$ \\
\hline \hline$A_{1}$ & 1 & 5 & 8 \\
\hline$A_{2}$ & $1 / 5$ & 1 & 5 \\
\hline$A_{3}$ & $1 / 8$ & $1 / 5$ & 1 \\
\hline
\end{tabular}

Table 8. Criterion layer judgment matrix B4.

\begin{tabular}{|c|c|c|c|}
\hline$c_{4}$ & $A_{1}$ & $A_{2}$ & $A_{3}$ \\
\hline \hline$A_{1}$ & 1 & 5 & 8 \\
\hline$A_{2}$ & $1 / 5$ & 1 & 5 \\
\hline$A_{3}$ & $1 / 8$ & $1 / 5$ & 1 \\
\hline
\end{tabular}

By above combination weight calculation result, it can be analyzed that in Chinese university students' main sports elective courses, badminton occupies $47.9 \%$, table tennis occupies $22 \%$, and basketball occupies $30.1 \%$. Thus, now the conclusion can be drawn that badminton selection rate in university students' sports elective courses is the highest, with the second highest being table tennis and basketball.

\section{CONCLUSION}

(1) The paper targeted recent years' Chinese university students' sports elective course status, by researching Chinese universities sports elective course setting purposes and universities sports elective course teaching management. By conducting analysis, the paper found out that main purposes of setting sports elective course are cultivating students to take an active part in sports and cultivating students' lifelong sports consciousness, and by researching teaching management, it is clear that presently, Chinese vocational colleges teaching management for university students' elective course is still not so perfect.

(2) The paper selected university students' sports elective course as research object, analyzed university students' sports elective course's influential factors, utilized analytic hierarchy process to establish AHP model, and then obtained conclusions that badminton selection rate in university students sports elective courses is the highest, with the second highest being table tennis and basketball.

\section{CONFLICT OF INTEREST}

The authors confirm that this article content has no conflict of interest.

\section{ACKNOWLEDGEMENTS}

Declared none.

\section{REFERENCES}

[1] W. Xiaoguang, "Thoughts and analyses of the construction of harmonious enterprises in China," Research On Development, vol. 5, pp. 57-60, 2007

[2] C. Nan - yue, "Harmonious society calls for society harmonious GDP," Journal of Yunnan Finance and Trade Institute, vol. 21, no. 6, pp. 81-85, 2005.

[3] L. Chang-ming, and G. Bin, "Power of harmony-against the background of chinese culture.,"Journal of Tianjin University (Social Sciences), vol. 11, no. 5, pp. 453-457, 2009.

[4] F. Liwei, and L. Jiyao, "The Development of the economy and society calls to create the new mode of economic development-"Green and Harmonious" development," Value Engineering, vol. 25, no. 5, pp. 29-31, 2006.

[5] S. Yi-kai, "The Father of Chinese Philosophy," Journal of Anhui University, vol. 30, no. 6, 2006.

[6] L. Jian-hua, "The two states of tao and the two forms of object,"Journal of Anhui University, vol. 30, no. 6, 5-6, 2001.

[7] XU Xiao-yue. Reflections on the Modern Value of the Ideas of Lao Zi. Journal of Anhui University (Philosophy \& Social Sciences), 2006, 30(6): 6-8.

[8] S. Bao-mei, L. Zong-xian, and L. Chang-ming, "Manifesto of harmonious ethics-for harmonious development of living beings and abiotic existence," Journal of Jinan University, vol. 12, no. 5), pp.1-10, 2002.

\section{(C) Chao Huang; Licensee Bentham Open.}

This is an open access article licensed under the terms of the (https://creativecommons.org/licenses/by/4.0/legalcode), which permits unrestricted, noncommercial use, distribution and reproduction in any medium, provided the work is properly cited. 